\title{
Kiraz (Prunus avium L.) Budama Artık Katsayısının ve Enerji Potansiyelinin Belirlenmesi
}

\author{
Mehmet Ali Mandacı* iD Gryasettin Çiçek \\ Çanakkale Onsekiz Mart Üniversitesi, Ziraat Fakültesi, Tarım Makinaları ve Teknolojileri Mühendisliği, 17100, Çanakkale \\ ${ }^{1}$ Sorumlu yazar: malimandaci@gmail.com
}

Geliş Tarihi: 04.01.2021

Kabul Tarihi: 27.05.2021

\section{$\ddot{O} \mathbf{z}$}

$\mathrm{Bu}$ çalışmada, Türkiye kiraz budama artıklarının enerji potansiyelinin ve bu potansiyelin hesaplanmasında kullanılabilecek gerçekçi budama katsayısının belirlenmesi hedeflenmiştir. Bu amaçla Çanakkale ilinde 3 farklı kiraz çeşidi ve her çeşit için 2 farklı yaş grubunda, toplam 30 kiraz ağacında budama çalışmaları yapılmıştır. Elde edilen veriler ile kiraza ait budama artık katsayısı belirlenmiştir. Yürütülen budama faaliyetlerinde, üç farklı kiraz çeşidi ve her çeşit için iki farklı yaş grubundan elde edilen budama artık miktarının ağaç başına ortalama 0-15 yaş arası çeşitlerde $6,76 \mathrm{~kg}, 15-30$ yaş arası çeşitlerde ise 16,61 kg olduğu belirlenmiştir. En fazla artık miktarı 15-30 yaş arası çeşitlerde sırasıyla 0900 Ziraat, Van ve Eşme çeşitlerinde belirlenmiştir. Türkiye' de kiraza ait enerji potansiyelinin belirlenmesi için yürütülen bu çalışmadan elde edilen veriler doğrultusunda budama artık katsayısının 11,68 $\mathrm{kg} \mathrm{ağaç}^{-1}$, kullanılabilir budama artık miktarının 204.816.430 kg y1l ${ }^{-1}$, Türkiye enerji potansiyelinin 3,43 $\mathrm{PJ} \mathrm{y}^{-1}{ }^{-1}$, Çanakkale enerji potansiyelinin ise $0,077 \mathrm{PJ} \mathrm{y}^{-1}$ olduğu tespit edilmiştir.

Anahtar Kelimeler: Enerji, Kiraz, Budama, Biyokütle, Katsayı

\section{Determination of Cherry Pruning Residual Coefficient and Energy Potential Abstract}

This study aimed to determine the energy potential of Turkey cherry prunings and the realistic pruning coefficient that can be used to calculate the energy potential of cherry prunings. For this purpose, pruning has been carried out in 3 different cherry varieties in Çanakkale and 2 different age groups for each variety, in a total of 30 cherry trees. With the data obtained, the pruning waste amount coefficient of the cherry was determined. In the pruning activities carried out, it was determined that the pruning residual amount obtained from three different age groups for three different cherry varieties and each variety was $6.76 \mathrm{~kg}$ per tree, and $16.61 \mathrm{~kg}$ for varieties between 15-30 years. In the varieties between the ages of 15-30, 0900 Ziraat is determined as Van and Eşme, respectively. Base dupon the data obtained from this study was carried out to determine the energy potential of the cherries in Turkey 11,68 pruning residual coefficients $\mathrm{kg}^{-1} \mathrm{tre}^{-1}$, available prunings amount of 204.816.430 kg year ${ }^{-1}$ of Turkey's energy potential 3,43 PJ year ${ }^{-1}$ It was determined that the energy potential of Çanakkale is 0,077 PJ year ${ }^{-1}$.

Keywords: Energy, Cherry, Pruning, Biomass, Coefficient

\section{Giriş}

Kiraz (Prunus avium L.) dünya üzerinde geniş bir dağ 11 lım göstermektedir. Ancak ticari anlamda üretimi Türkiye, ABD (Amerika Birleşik Develetleri), İran ve İtalya gibi ülkelerde yapılmaktadır. Yıllara ve iklim şartlarına göre değişmekle beraber dünya kiraz üretiminde ilk sıralarda yer alan Türkiye, kiraz ihracatında da söz sahibi ülkelerden biridir (Şekil 1).

Türkiye'nin önemli kiraz üretim merkezlerinden birisi olan Çanakkale'nin Lapseki ilçesinde 2019 yılında toplam 6.480 ton kiraz üretimi gerçekleşmiştir. Bunun 3.400 tonu İngiltere ve Rusya başta olmak üzere pek çok Avrupa ülkesine ihraç edilmiştir (Anonim, 2013). Kiraz ağaçları meyve vermeye 5-7 yıl sonra başlar, tam verime 10-12 yaşında ulaşır, ekonomik ömürleri ise 25-30 yıldır (Anonim, 2020). Tüm vejetasyon süreci boyunca kiraz ağaçlarında yıllık olarak budama yapılmaktadır. Yapılan budama faaliyetleri sonrası genellikle budama artıkları bahçe içinde ya da bahçe dışında yakılarak yok edilmektedir. Bu işlemler budama artıklarının biyo-yakıt kaynağı olarak değerlendirilmesini engelleyerek, enerji kaybına yol açmasının yanısıra atmosfere fazla karbon salınımına neden olur. Biyo-yakıtlar için tarımsal kaynaklar, bitkisel ve hayvansal artıklar önemli bir 
potansiyel oluşturmaktadır. Organik madde içeren artıkların değerlendirilmesi, çevre kirliliği ve temiz enerji üretimi bakımından önem taşımaktadır. Bu amaçla özellikte gelişmekte olan ülkelerde kullanımı en yaygın olan kaynak biyokütledir. Dünya enerji tüketiminin yaklaşık \%15'i biyokütleden sağlanmaktadır. Bu oran gelişmekte olan ülkelerde ise yaklaşık \%43'tür (Başçetinçelik ve ark., 2006). Biyokütle; her yerde yetiştirilebilmesi, çevre korunmasına katkısı, elektrik üretimi, kimyasal madde ve özellikle taşıtlar için yakıt olabilmesi nedeni ile stratejik bir enerji kaynağı olarak kabul edilmektedir.

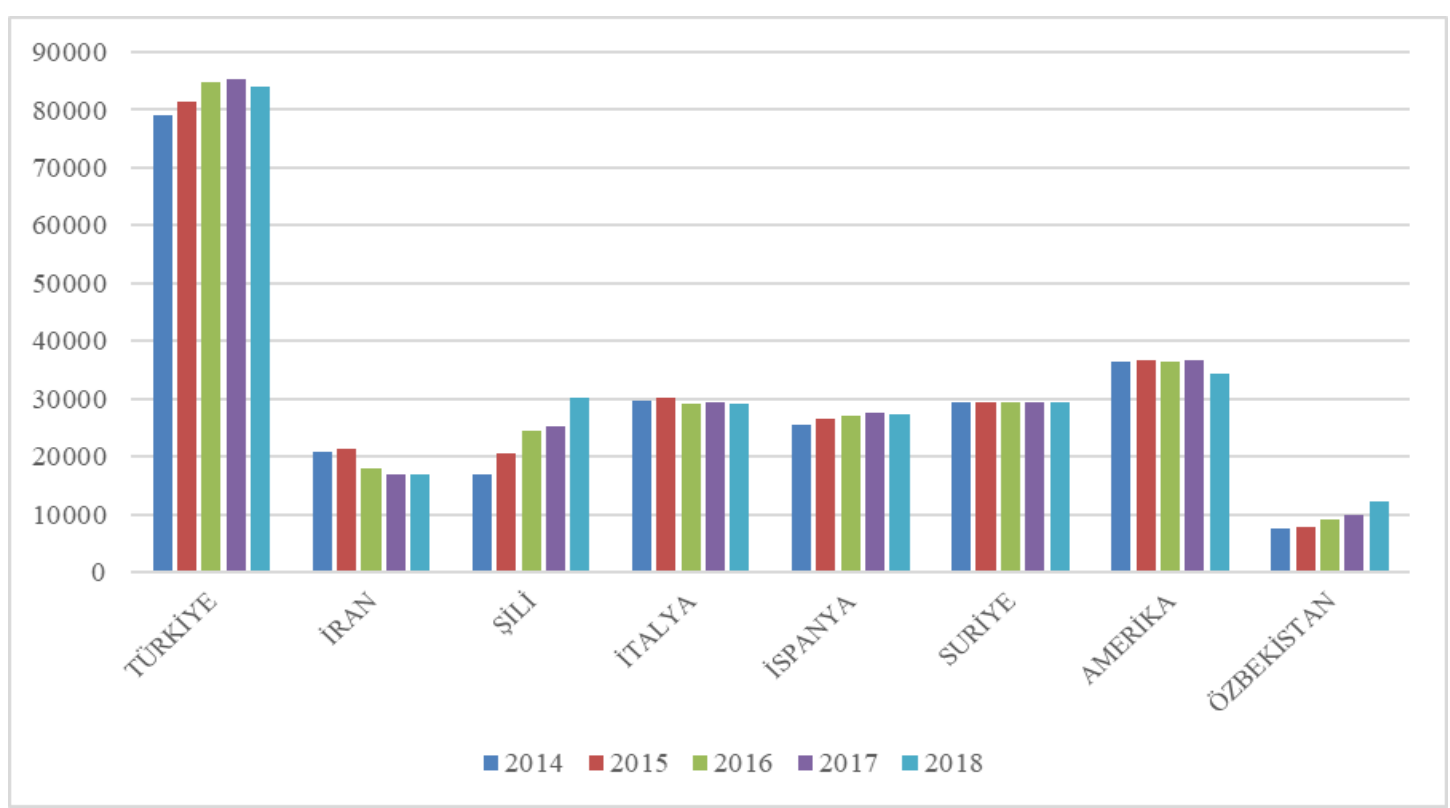

Şekil 1. Dünya'da yıllara ve ülkelere göre kiraz üretim alanı (ha) (FAO, 2019).

Biyokütle enerji kaynakları içerisinde yer alan meyve ağaçlarından elde edilen budama artıkları, ülkemizde önemli bir potansiyele sahiptir (Çizelge 1). Bilandzija ve ark. (2012), ise Hırvatistan'da kiraz için yapmış oldukları araştırmalarında her ağaç için ortalama $5,90 \mathrm{~kg} \mathrm{ağaç}^{-1} \mathrm{ve}$ budama artık miktarını 1.988,3 $\mathrm{kg} \mathrm{ha}^{-1}$ olarak tespit etmişlerdir. Araştırıcılar, Amerika Birleşik Devletleri Kaliforniya Enerji Komisyonu raporunda (CEC, 2015), Kaliforniya eyaletinde şeftali budama artık miktarının belirlenmesine yönelik budama katsayısının 5 ton ha $^{-1} \mathrm{y}^{-1}{ }^{-1}$ ve elde edilen artıkların enerji amaçlı kullanılabilirlik oranının $\% 70$ olduğunu rapor etmişlerdir.

Sümer ve ark. (2016), zeytin üretiminde artık potansiyelinin belirlenmesinde gerçekçi bir yaklaşım sunulmasını amaçlamışlardır. Çanakkale ilinin zeytin üretimi artıklarının oluşturduğu biyokütle potansiyeli belirlenmiş, enerji ve diğer amaçlar için geri kazanım olanaklarını araştırmışlardır. 2011-2015 yılları arasındaki istatistikleri kapsayan çalışmada, Çanakkale'de pirina ve karasu için toplam metan üretim potansiyelinin $8.803 .909 \mathrm{~m}^{3} \mathrm{y}^{-1}{ }^{-1}$ olduğunu saptamışlardır. Pirina ve budama artıklarının 1sıl kapasitesi ise 1.548.611 GJ yı1 ${ }^{-1}$ olduğunu bildirmişlerdir. Çanakkale'de pirina ve budama artıkları kaynaklı biyokömür potansiyelinin 27.796 ton $\mathrm{y}^{1}{ }^{-1}$ olduğunu belirlemişlerdir.

Bahçe bitkilerinin yıllık toplam üretimi ve artık miktarlarının teorik olarak hesaplanan toplam 1s1l değeri yaklaşık $75 \mathrm{PJ}_{\text {y1 }}{ }^{-1}$ olduğu, toplam içerisindeki en büyük 1s1l değere sahip ürünlerin ise $\% 56,3$ ile findık ve \%25,2 ile zeytin olduğu bildirilmiştir (Başçetinçelik ve ark., 2015). Zivkovic ve ark. (2013), Sırbistan'da meyve ağaçları ve üzüm budama artıklarının enerji potansiyelinin belirlenmesine yönelik yaptıkları çalışmada kiraza ait toplam ağaç sayısının 8.377.000 adet, enerji potansiyelinin 18,65 $\mathrm{MJ} \mathrm{kg}^{-1}$, kullanılabilir enerji oranının \%64,87, kullanılabilir enerji miktarının $12,10 \mathrm{MJ} \mathrm{kg}^{-1}$ olduğunu toplamda Sırbistan'da kiraza ait enerji miktarını 1.82.451 GJ ha-1 olduğunu bildirmişlerdir. Ünal ve Alibaş (2007), Türkiye'de yaptıkları çalışmada, kültüre alınan meyve veren kiraz ağaçlarının toplam alanının 7.517,5 ha, kalıntı kuru miktarının $49,3 \times 10^{3}$ t, kullanılabilir budama miktarının $9,8 \times 10^{3}$ t olduğunu bildirmişlerdir. Çiçek ve ark. (2019), Çanakkale ilinde şeftali ağaçlarında budama sonucu oluşan artıkların kütle miktarları dikkate alınarak, budama artık katsayılarının belirlenmesini amaçlamışlardır. Çalışmada 5-10 yaş aralığında 3 farklı şeftali çeşidi için, budama artık katsayıları belirlenmiş ve katsayılar kullanılarak, Çanakkale ili ve Türkiye geneli için 
şeftali yetiştiriciliği kaynaklı budama artık ve enerji potansiyelini hesaplanmışlardır. Üç çeşidi temsil eden $7,08 \mathrm{~kg} \mathrm{ağaç}^{-1} \cdot \mathrm{yll}^{-1}$ ortalama değerin, Türkiye şeftali üretimi budama artıkları belirleme katsayısı olarak kullanılabileceğini bildirmişlerdir.

Çizelge 1. Türkiye toplam bahçe bitkileri üretimi ve artık miktarları (Başçetinçelik ve ark., 2015).

\begin{tabular}{lrrrrr} 
Ürünler & Üretim (ton) & Alan (ha) & $\begin{array}{r}\text { Artık } \\
\text { Miktarı } \\
\text { (ton) }\end{array}$ & $\begin{array}{r}\text { Birim Isıl } \\
\text { Değeri } \\
\text { (MJ/kg) } \\
\text { (Teorik) }\end{array}$ & $\begin{array}{r}\text { Toplam Isıl } \\
\text { Değeri (GJ) } \\
\text { (Teorik) }\end{array}$ \\
\hline Fındık & 652.803 & 286.697 .887 & 2177986 & 19 & 33.105 .388 \\
Zeytin & 1.496 .630 & 90.208 .994 & 441.254 & 18.1 & 3.993 .345 \\
Portakal & 1.180 .851 & 11.884 .275 & 237.686 & 17.6 & 3.346 .612 \\
Antepfıstığı & 42.926 & 29.600 .005 & 209.611 & 19 & 3.186 .080 \\
Mandarin & 592.884 & 8.619 .163 & 103.430 & 17.6 & 1.456 .294 \\
Kayısı & 467.903 & 11.288 .357 & 86.964 & 19.3 & 1.342 .719 \\
Limon & 475.159 & 5.529 .038 & 88.465 & 17.6 & 1.245 .582 \\
Vişne & 114.466 & 4.446 .680 & 21.400 & 19 & 325.279 \\
Ceviz & 115.698 & 3.737 .868 & 50.480 & 19 & 479.563 \\
Badem & 46.701 & 3.631 .622 & 28.500 & 18.4 & 419.521 \\
Greyfurt & 126.285 & 894.293 & 14.309 & 17.6 & 201.466 \\
\hline
\end{tabular}

Türkiye'de meyve yetiştiriciliğinde kiraz ekonomik anlamda üst sıralarda yer almakta ve geniş alanlarda yetiştiriciliği yapılmaktadır. Literatür araştırmalarında Türkiye'de kiraza ait budama artıklarının gerçekçi budama katsayısı ve enerji potansiyeli bulunmamakta fakat teorik veriler ile potansiyel budama miktarı ve enerji değerleri bulunmaktadır.

Yürütülen bu çalışma sonucunda Türkiye'deki kiraz ağaçları budama artıklarından elde edilebilecek budama katsayısı değeri ve potansiyel enerji miktarı gerçekçi veriler ile ortaya konulup, artıkların enerjiye dönüştürülmesine yönelik geliştirilecek yöntem ve teknolojilere katkı sağlanmış olacaktır.

\section{Materyal ve Yöntem}

Çalışmanın zamanı, meyvecilikte genel budama zamanı olan Şubat ve Mart ayları olarak belirlenmiştir. Budama ekibi ile eş zamanlı çalışma yürütülmüş ve ölçümler yapılmıştır. Çalışmadan elde edilen veriler;

$\begin{array}{ll}\text { Budama artık miktarının tespiti } & \left(\mathrm{kg} \mathrm{ağaç}{ }^{-1}\right) \\ \text { Budama öncesi ağaç yüksekliği } & (\mathrm{m}) \\ \text { Budama sonrası ağaç yüksekliği } & (\mathrm{m}) \\ \text { Budama öncesi taç genişliği } & (\mathrm{m}) \\ \text { Budama sonrası taç genişliği } & (\mathrm{m}) \\ \text { Budama için harcanan süre } & (\mathrm{dk}) \\ \text { Budama artıkları nem miktarı } & (\%) \text { olarak belirlenmiştir. }\end{array}$

Çalışmada 2 kişilik budama ekibi, 2 adet uzunluk ayarlı budama makası, ölçüm için dijital el kantarı $(0,001 \mathrm{~kg}$ hassasiyette), şerit metre, hassas terazi ve kurutma firını kullanılmıştır. Budama öncesi her bir örnek ağacın yüksekliği ve taç genişliği şerit metre ile ölçülüp kayıt altına alınmıştır. Budama ekibi çalışmaya başladığında her bir ağaç için harcanan süre kronometre ile belirlenip kaydedilmiştir. Budama sonrası her bir örnek ağacın tekrar yükseklik ve taç çapları şerit metre ile 
tekrar ölçülüp kayıt altına alınmıştır. Son olarak budama artık katsayının belirlenmesinde kullanılacak olan budama artıkları dijital kantar ile tartılarak kayıt altına alınmıştır.

Materyal nem içeriği ASAE D245.6 standardına göre belirlenmiştir. Materyal örnekleri, kurutmadan önce ve sonra tartılır. Örnekler 24 saat süre ile $105{ }^{\circ} \mathrm{C}$ sicaklıkta kurutma firınında kurutulur. Belirlenen kütle farkı, kurutmadan önceki materyal kütlesine bölünerek, aşağıdaki eşitlik yardımıyla yaş bazda nem içeriği belirlenir (Küsek ve ark., 2015).

$$
\mathrm{NI}=\left[\frac{\mathrm{YÜK}-\mathrm{KÜK}}{\mathrm{YÜK}}\right] \times 100
$$

Nİ = nem içeriği (\%), YÜK = yaş ürün kütlesi $(\mathrm{kg}), \mathrm{KÜK}=$ kuru ürün kütlesidir $(\mathrm{kg})$

Çanakkale ili içerisinde belirlenen kiraz bahçelerinde en çok yetiştirilen ve Türkiye'deki tüm kiraz ağaçlarını temsil edebilecek yaygınlıkta olan ve üretimimizin hemen hemen tamamını oluşturan 0900 Ziraat (Anonim, 2011)., Van ve Eşme olmak üzere 3 farklı çeşit ve 2 farklı yaş grubu $(0-15,15$ 30) olmak üzere tesadüf blokları deneme desenine göre 5 tekerrürlü olarak yürütülmüştür. Elde edilen veriler Çok Yönlü Varyans Analizi tekniği kullanılarak istatistiksel olarak değerlendirilmiştir $(P \leq$ $0,05)$. Gruplar arası farklılığın ortaya konulması için Tukey testi uygulanmıştır.

Türkiye'de meyve veren kiraz ağacı sayıs1 21.114.922 adet, meyve vermeyen ağaç sayısı 5.917.070 adet, toplamda ise 27.031.992 adettir. Çanakkale'de meyve veren kiraz ağacı sayıs1 536.350 adet, meyve vermeyen ağaç sayısı 74.136 adet, toplamda ise 610.486 adettir (TÜIK, 2019).

Kiraz'a ait budama artıklarından elde edilen birim enerji değeri $16,76 \mathrm{MJ} \mathrm{kg}^{-1}$ olarak bildirilmiştir (Bilandizja, 2012). Kiraz budama artık miktarının kullanılabilirlilik oranının \%64,87 olduğu bildirilmiştir (Zivkovic ve ark., 2013).

Enerji potansiyel değerlerinin belirlenmesinde, bu çalışmadan elde edilen budama artık katsayısı, kiraza ait TÜİK 2019 verileri, Bilandizja'nın, 2012'de Hırvatistan'da yaptığı çalışmadan elde ettiği kiraza ait budama artıklarının birim enerji değeri olan $16,76 \mathrm{MJ} \mathrm{kg}{ }^{-1}$ ile Zivkovic ve arkadaşkarının 2013 yaptıkları çalışmadan elde ettikleri kiraz budama artık miktarının kullanılabilirlilik oranı \%64,87 değerinden yararlanılmıştır.

\section{Bulgular ve Tartıșma}

Yürütülen budama faaliyetlerinde, üç farklı kiraz çeşidi ve iki farklı yaş grubundan elde edilen budama artık miktarının 0-15 yaş arası çeşitlerde ağaç başına ortalama 6,76 kg, 15-30 yaş arası çeşitlerde ise 16,61 kg olduğu belirlenmiştir. En fazla artık 15-30 yaş arası çeşitlerde sırasıyla 0900 Ziraat, Van ve Eşme olarak belirlenmiştir (Çizelge 2).

Çizelge 2. Çalışmadan elde edilen istatistiksel sonuçlar

\begin{tabular}{|c|c|c|c|c|c|c|c|c|}
\hline Çeşit & Yaş & $\begin{array}{c}\text { Budama } \\
\text { miktarı }(\mathrm{kg})\end{array}$ & $\begin{array}{l}\text { Budama } \\
\text { öncesi } \\
\text { bitki boyu } \\
\text { (m) }\end{array}$ & $\begin{array}{c}\text { Budama } \\
\text { sonrasi } \\
\text { bitki boyu } \\
\text { (m) }\end{array}$ & $\begin{array}{l}\text { Budama } \\
\text { öncesi } \\
\text { ağaç taç } \\
\text { genişliği } \\
\text { (m) }\end{array}$ & $\begin{array}{l}\text { Budama } \\
\text { sonrası } \\
\text { ağaç taç } \\
\text { genişliği } \\
\text { (m) }\end{array}$ & $\begin{array}{c}\text { Budama } \\
\text { süresi (dk) }\end{array}$ & $\begin{array}{c}\text { Nem değer } \\
(\%)\end{array}$ \\
\hline $\begin{array}{c}0900 \\
\text { Ziraat }\end{array}$ & & $\begin{array}{c}10.74 \pm 1.67 \\
\mathrm{AB}\end{array}$ & $\begin{array}{c}5.00 \pm 0.30 \\
\mathrm{AB}\end{array}$ & $\begin{array}{c}3.47 \pm 0.21 \\
\text { B }\end{array}$ & $\begin{array}{c}4.14 \pm 0.13 \\
\text { B }\end{array}$ & $\begin{array}{c}3.32 \pm 0.11 \\
\text { B }\end{array}$ & $\begin{array}{c}4.26 \pm 0.90 \\
\mathrm{~A}\end{array}$ & $\begin{array}{c}52.57 \pm 0.41 \\
\mathrm{~A}\end{array}$ \\
\hline Van & $0-15$ & $\begin{array}{c}4.80 \pm 0.77 \\
\text { B }\end{array}$ & $\begin{array}{c}3.74 \pm 0.86 \\
\text { B }\end{array}$ & $\begin{array}{c}3.71 \pm 0.13 \\
\text { B }\end{array}$ & $\begin{array}{c}3.39 \pm 0.27 \\
\text { B }\end{array}$ & $\begin{array}{c}2.93 \pm 0.33 \\
\mathrm{~B}\end{array}$ & $\begin{array}{c}4.01 \pm 0.96 \\
\mathrm{~A}\end{array}$ & $\begin{array}{c}52.05 \pm 0.24 \\
\mathrm{~A}\end{array}$ \\
\hline Eşme & & $\begin{array}{c}4.75 \pm 1.18 \\
\mathrm{~B} \\
\end{array}$ & $\begin{array}{c}3.87 \pm 0.46 \\
\text { B }\end{array}$ & $\begin{array}{c}3.44 \pm 0.42 \\
\text { B }\end{array}$ & $\begin{array}{c}3.51 \pm 0.62 \\
\mathrm{~B} \\
\end{array}$ & $\begin{array}{c}3.01 \pm 0.46 \\
\mathrm{~B}\end{array}$ & $\begin{array}{c}4.42 \pm 1.08 \\
\mathrm{~A}\end{array}$ & $\begin{array}{c}53.59 \pm 0.75 \\
\mathrm{~A}\end{array}$ \\
\hline $\begin{array}{c}0900 \\
\text { Ziraat }\end{array}$ & & $\begin{array}{c}17.67 \pm 3.54 \\
\mathrm{~A}\end{array}$ & $\begin{array}{c}6.03 \pm 0.29 \\
\mathrm{~A}\end{array}$ & $\begin{array}{c}4.43 \pm 0.22 \\
\mathrm{AB}\end{array}$ & $\begin{array}{c}4.66 \pm 0.45 \\
\mathrm{AB}\end{array}$ & $\begin{array}{c}4.25 \pm 0.43 \\
\mathrm{AB}\end{array}$ & $\begin{array}{c}9.71 \pm 3.00 \\
\mathrm{~A}\end{array}$ & $\begin{array}{c}51.80 \pm 1.06 \\
\mathrm{~A}\end{array}$ \\
\hline Van & $15-30$ & $\begin{array}{c}16.62 \pm 2.01 \\
\mathrm{~A}\end{array}$ & $\begin{array}{c}6.51 \pm 0.38 \\
\mathrm{~A}\end{array}$ & $\begin{array}{c}4.42 \pm 0.33 \\
\mathrm{AB}\end{array}$ & $\begin{array}{c}4.52 \pm 0.47 \\
\mathrm{AB}\end{array}$ & $\begin{array}{c}3.41 \pm 0.13 \\
\text { B }\end{array}$ & $\begin{array}{c}6.81 \pm 0.79 \\
\mathrm{~A}\end{array}$ & $\begin{array}{c}51.93 \pm 1.08 \\
\mathrm{~A}\end{array}$ \\
\hline Eşme & & $\begin{array}{c}15.55 \pm 2.62 \\
\mathrm{~A}\end{array}$ & $\begin{array}{c}6.10 \pm 0.36 \\
\mathrm{~A}\end{array}$ & $\begin{array}{c}5.07 \pm 0.22 \\
\mathrm{~A}\end{array}$ & $\begin{array}{c}6.14 \pm 0.46 \\
\mathrm{~A}\end{array}$ & $\begin{array}{c}5.71 \pm 0.38 \\
\mathrm{~A}\end{array}$ & $\begin{array}{c}10.51 \pm 1.78 \\
\mathrm{~A}\end{array}$ & $\begin{array}{c}54.44 \pm 1.07 \\
\mathrm{~A}\end{array}$ \\
\hline
\end{tabular}


* Her özellik kendi içinde çeşit ve yaş faktörlerinin birlikte etkisine göre harflendirilmiştir.

Yapılan istatistiksel analizler sonucunda çeşit faktörünün, budama sonrası taç genişliğine etkisi $(P$ : 0,007) ve nem değerine etkisi $(P: 0,046)$ istatistiksel olarak önemli bulunmuştur. Yaş faktörünün ise budama miktarına etkisi $(P: 0,000)$, budama öncesi bitki boyuna etkisi $(P: 0,000)$, budama sonrası bitki boyuna etkisi ( $P$ : 0,000), budama öncesi ağaç taç genişliğine etkisi $(P: 0,001)$, budama sonrası ağaç taç genişliğine etkisi $(P$ : 0,000), budama süresine etkisi $(P: 0,001)$ istatistiksel olarak önemli bulunmuştur. Çalışma neticesinde her bir özellik için genel ortalamalara göre katsayılar elde edilmiştir (Çizelge 3).

Çizelge 3. Çalışmadan elde edilen katsayılar

\begin{tabular}{|c|c|c|c|c|c|c|c|c|}
\hline & & $\begin{array}{r}\text { Budama } \\
\text { miktar1 } \\
\left(\mathrm{kg} \mathrm{ağaç}^{-1}\right)\end{array}$ & $\begin{array}{r}\text { Budama } \\
\text { öncesi } \\
\text { bitki } \\
\text { boyu (m) }\end{array}$ & $\begin{array}{r}\text { Budama } \\
\text { sonras1 } \\
\text { bitki } \\
\text { boyu }(\mathrm{m})\end{array}$ & $\begin{array}{r}\text { Budama } \\
\text { öncesi } \\
\text { ağaç taç } \\
\text { genişliği } \\
(\mathrm{m})\end{array}$ & $\begin{array}{r}\text { Budama } \\
\text { sonrasi } \\
\text { ağaç taç } \\
\text { genişliği } \\
(\mathrm{m})\end{array}$ & $\begin{array}{r}\text { Budama } \\
\text { süresi } \\
(\mathrm{dk})\end{array}$ & $\begin{array}{r}\text { Nem } \\
\text { değeri } \\
(\%)\end{array}$ \\
\hline \multirow{3}{*}{ Çeşit } & 0900 Ziraat & 14.20 & 5.51 & 3.95 & 4.40 & 3.78 & 6.98 & 52.18 \\
\hline & Van & 10.71 & 5.12 & 4.06 & 3.95 & 3.17 & 5.41 & 51.99 \\
\hline & Eşme & 10.15 & 4.98 & 4.25 & 4.82 & 4.36 & 7.47 & 54.01 \\
\hline \multirow{2}{*}{ Yaş } & $0-15$ & 6.76 & 4.20 & 3.54 & 3.68 & 3.08 & 4.23 & 52.73 \\
\hline & $15-30$ & 16.61 & 6.21 & 4.64 & 5.10 & 4.45 & 9.01 & 52.72 \\
\hline GENEL & & 11.68 & 5.20 & 4.09 & 4.39 & 3.77 & 6.62 & 52.73 \\
\hline
\end{tabular}

Kiraz ağaçlarının budanmasından elde edilen artıklardan olası bir enerji kaynağı olarak yararlanılması üzerine yapılan bu çalışmaya benzer çalışmalarda araştırmacılar tarafından budama artık potansiyelinin teorik olarak belirlenmesini sağlayacak katsayılar ortaya konulmuştur. Bilandzija ve ark. (2012), Hırvatistan' da kiraz için yapmış oldukları araştırmalarında ağaç başına ortalama 5,90 kg ağaç ${ }^{-1}$, ve birim alana 1.988,3 kg ha ${ }^{-1}$ budama artığı tespit etmişlerdir. Bilandzija ve ark. (2012), çalışmalarında budama artıklarının birim ağırlığının enerji potansiyelini $17.727 \mathrm{MJ} \mathrm{kg}^{-1}$, birim alan enerji potansiyelini ise 50.881,10 $\mathrm{MJ} \mathrm{ha}^{-1}$ olarak tespit etmişlerdir.

Ancak çeşitli araştırmacılar tarafından farklı ülkelerde yürütülen budama artığı katsayısı ile ilgili benzer çalışmalarda, birim alana düşen budama artık miktarı cinsinden katsayılar belirlenmiş ve kullanılmıştır. İncelenen sonuçlara göre söz konusu katsayıların önemli düzeyde farklar içerdiği görülmektedir. Budama artık potansiyelinin belirlenmesine yönelik çalışmalarda, birim alan için belirlenen katsayılar yerine, ağaç başına belirlenen artık miktarı katsayısının kullanımı ile dikim farklılıklarının oluşturduğu olumsuzlukların elimine edilebileceğine değinilmiştir (Çiçek, 2019).

Zivkovic ve ark. (2013) ise kiraz budama artıklarının birim ağırlığının enerji potansiyelini en yüksek 18,65 MJ kg-1, ortalama $12,10 \mathrm{MJ} \mathrm{kg}^{-1}$ olarak tespit etmiş ve hesaplamalarında bu değeri kullanarak ağaç başına elde edilen budama artıklarının sahip olduğu enerji miktarını 21,78 $\mathrm{MJ}$ ağaç olarak belirlemişlerdir ancak yapılan çalışmada ağaç yaşı, çeşidi ve budama yöntemi ile ilgili bir yöntem sunmamışlardır. Bu çalışmada ise denemeye ait örneklerin yaş grupları, çeşitleri belirtilerek çok daha geniş spekturumlu bir deneme deseni oluşturulmuştur. Budama artık miktarları ile ilgili oluşan farkın bu sebeplerden kaynaklanabileceği düşünülmektedir. Yapılan bu çalışmadan elde edilen verilere göre kiraza ait ortalama budama miktarı (budama artık katsayısı) 11,68 kg ağaç ${ }^{-1}$, enerji potansiyeli ise 126,99 MJ ağaç ${ }^{-1}$ olarak tespit edilmiştir. Bu tespite dayanarak Türkiye genelinde teorik olarak kiraz budama artık miktarının enerji potansiyeli belirlenmiştir (Çizelge 4).

Tüm sonuçlar değerlendirildiğinde kiraz, Türkiye meyve ağaçlarına ait budama artıklarının enerji potansiyeli sıralamasında fındık ve zeytinden sonra 3. sıraya yerleşmiştir. Ayrıca teorik olarak hesaplanan Türkiye'de kiraz budama artıklarından elde edilebilecek potansiyel enerjinin, Türkiye yıllık enerji ihtiyacının \%6,34’ünü karşılayabileceği sonucuna varılmıştır. 
Çizelge 4. Türkiye'de kiraz budama artıklarının enerji potansiyeli

Ağaç sayısı Toplam artık miktarı Kullanılabilir artık (Adet) $\quad\left(\mathrm{kg} \mathrm{y}^{-1}{ }^{-1}\right) \quad$ miktarl $\left(\mathrm{kg} \mathrm{y}^{-1}{ }^{-1}\right)$

Toplam enerji potansiyeli $\left(\mathrm{PJ} \mathrm{y}^{-1} 1^{-1}\right)$

\begin{tabular}{lrrrr}
\hline Türkiye & 27.031 .992 & 315.733 .667 & 204.816 .430 & 3.43 \\
Çanakkale & 610.486 & 7.130 .476 & 4.625 .541 & 0.077 \\
\hline
\end{tabular}

Yapılan araştırmalarda açıkça görülmektedir ki, budama artıklarının katsayısının belirlenmesinde daima teorik yaklaşımlar ortaya konulmuştur. Bu çalışmada ise, kiraz budama artıklarının katsayısının belirlenmesinde gerçekçi bir yaklaşım ortaya konularak, nicel anlamda araştırma sonuçları bulunup sonraki çalışmalara 1şık tutması yönünden belirleyici olmuştur. Ayrıca yapılan literatür taramalarında Türkiye'de kiraza ait budama artık katsayısının tespitine yönelik bir çalışmaya rastlanmamıştır. Bu anlamda literatürde oluşan bu boşluğu doldurmak adına bu çalışmanın önemli bir katkı sağlayacağı düşünülmektedir. Türkiye'de 2023 yılına kadar birincil enerji talebinin yaklaşık \%90 oranında artacağı tahmin edilmektedir. T.C Enerji ve Tabii Kaynaklar Bakanlığı tarafından öngörülen bu projeksiyonda yenilenebilir kaynaklardan elde edilen enerji kullanım payının \%30'a çıkarılması hedeflenmekte ve biyokütle kaynaklarının kullanımının toplam birincil enerji talebi içerisindeki oranının \%2 olması öngörülmektedir (ETKB, 2013). Tarım ve hayvancılığın yoğun olarak yapıldığı ülkemizde tarımsal artıklar ve modern yöntemler ile geri kazanımı konusunda farkındalık yaratacak proje ve diğer faaliyetler doğrultusunda, bilim insanları, kamu kurum ve kuruluşları, sivil toplum örgütleri ve özel sektör temsilcilerinin katkı sağlayacağı kırsal ve kentsel bölgeye dayalı organizasyonların arttırılması gerekmektedir.

Not: Bu makale Zir. Yük. Müh. Mehmet Ali MANDACI'nın Kiraz (Prunus avium L.) Budama Artık Katsayısının ve Enerji Potansiyelinin Belirlenmesi adlı Yüksek Lisans Tezinden üretilmiştir.

\section{Kaynaklar}

Anonim, 2011. https://arastirma.tarimorman.gov.tr/marem/Belgeler E.T. 23.01.2020

Anonim, 2013. www.haberler.com/lapseki-kirazi E.T. 24.01.2020.

Anonim, 2020. https://adana.tarimorman.gov.tr/ E.T. 24.01.2020.

Başçetinçelik, A., Öztürk, H.H., Kaya, D., Kaçıra, M., Ekinci, K., Karaca, C., 2006. Türkiye'de Jeotermal Enerji Kullanımını Geliştirme Olanakları, VI. Ulusal Temiz Enerji Sempozyumu Bildiri Kitabı: 846-857, 2527 Mayis 2006, Isparta.

Başçetinçelik, A., Öztürk, H., Karaca, C., 2015. Türkiye'de Biyokütleden Enerji Üretimi Olanakları mmo.org.tr. E.T. 10.12.2019.

Bilandzija, N., Voca, N., Kricka, T., Matin, A. and Jurisic, V., 2012. Energy Potential of Fruit Tree Pruned Biomass in Croatia. Spanish Journal of Agriculture Research. 10(2): 292-298.

CEC, 2015. California Energy Commission. An Assessment of Biomass Resources in California. University of California, Davis, Consultant Report.

CIGR, 1999. Handbook of Agricultural Engineering V:5 Energy And Biomass Engineering. ASAE. pp: 262.

Cristensen, J.V., 1985. Production of Cherries in Western Europe. ActaHorticulture. 69: 15-26.

Çiçek, G., Sümer, S.K., Egesel, C.E., Say, S.M., 2019. Şeftali Ağacı Budama Artık Potansiyelinin Hesaplanmasına Yönelik Katsayının Belirlenmesi. ÇOMÜ Ziraat Fakultesi Dergisi. 7(2): 299-305.

ETKB, 2103. Dünyada ve Türkiye'de Enerji Görünümü. Enerji ve Tabii Kaynaklar Bakanlığı Sunumu, Ankara. FAO, 2019. http://www.fao.org. E.T. 22.12.2020.

Sümer, S.K., Çiçek, G., Say, S.M., 2016. Çanakkale İlinde Zeytin Üretimi Artık Potansiyelinin Belirlenmesi ve Değerlendirme Olanaklarının Araştırılması. Tarım Makinaları Bilimi Dergisi. 12(2): 103-111.

Kösek, G., Güngör, C., Öztürk, H.H., Akdemir, Ş., 2015. U. Ü. Ziraat Fakültesi Dergisi. 29(2): 137-145. TÜIK, 2019. Konularına Göre İstatistikler. https://biruni.tuik.gov.tr/medas/?kn=92\&locale=tr E.T. 06.07.2020. Ünal, H., Alibaş, K., 2007. Agricultural Residues as Biomass Energy, Energy Sources. Part B, 2(2): 123-140.

Zivkovic, M., Urosevic, M., Oljaca, S., Oljaca, M., Gligoveric, K., Zlatanovic, I., Koprivica, R., 2013. Aspects of Using Potential Energy Products of Biomass after Pruning Fruit and Grape Plantations in the Republic of Serbia. Agriculture \&Forestry 59(1): 167-182. 